March - 2005

\title{
Using Integrated Enterprise Systems to Achieve Strategic Goals: A case study of a dual mode university
}

\author{
Alan Smith \\ Distance and e-Learning Centre \\ University of Southern Queensland \\ Toowoomba, Australia
}

\begin{abstract}
Since 1999, the University of Southern Queensland has embarked on a range of initiatives designed to improve the infrastructure and systems used to support its widely ranging activities in teaching and learning and research and its expansion into new international markets. This has involved the careful selection and implementation of various enterprise systems, together with the use of horizontal process teams. The results of this approach are now being realized, with demonstrable improvements to many university services, together with significant cost efficiencies. This paper discusses the reasons for the changes, the processes used to drive the changes through the various university committee structures, and the outcomes of the implementation of the enterprise systems.
\end{abstract}

Keywords: higher education; enterprise systems; change management; integrated systems

\section{Introduction}

Established in 1967 as a conventional tertiary education institution, the University of Southern Queensland (USQ) became a dual mode institution in 1977, when it began offering courses via distance education (see also Reid, this issue). Today, USQ teaches and researches as a dual mode university (that is, with on- and off-campus student populations), and also with triple option teaching styles (that is, students can study on-campus by 'traditional' distance education, or online via the Internet). It offers well in excess of 100 full degree awards, consisting of over 1,000 subjects/ courses across five faculties. The university provides access to educational opportunities to approximately 25,000 students annually, with about 19,000 studying via distance education and the remaining 6,000 on-campus at the Toowoomba and Wide Bay campuses. USQ's student enrollment is truly multicultural, with students from more than 100 different countries.

Since the late 1990s, USQ has embarked upon a range of initiatives designed to improve the infrastructure and systems used to support its widely ranging activities in teaching and learning, research, and its expansion into new international markets (see also Cummings, Phillips, Tilbrook and Lowe; Nunan; Reid; Inglis; McConachie, Danaher, Luck, and Jones, this issue). This has involved the careful selection and implementation of various enterprise systems (see also 
McConachie and Danaher; McConachie, Danaher, Luck, and Jones, this issue), together with the use of horizontal process teams. The results of this approach are now being realized, with demonstrable improvements to many university services, together with significant cost efficiencies. This paper discusses the reasons for the changes, the processes used to drive the changes through the various university committee structures, and the outcomes of the implementation of the enterprise systems. The paper also provides an account of the lessons learned during the implementation and the next steps which have emerged from this approach.

USQ has progressively developed its physical and technical infrastructure over its 38 year history. Its development as a strong community-based regional higher educational institution with a strong focus on student-centered education has positioned it to become a leading innovator in the use of educational technologies. This, in turn, enabled it to expand its influence as a national and global provider. USQ is a regional university with strong community links, a flexible education provider offering higher education opportunities for Australians nationally, and an international provider of quality higher education experiences to international students both on-campus in Australia and offshore. USQ's mission will continue to be as a higher education leader in transnational education which is regionally based and globally focused (University of Southern Queensland, 2004b).

USQ also continues to develop its 'University Cities' concept built on community partnerships, service, and engagement, while implementing strategies for internationalization that bring benefits and opportunities to its regions. USQ aims to prosper in a highly dynamic and challenging operating environment. Growth is planned for all USQ campuses, and nationally and internationally through flexible learning, to help achieve further recognition of USQ as a potent regional presence and to secure USQ's position as a successful local, national, and international business (University of Southern Queensland, 2004b).

What led the USQ senior management to decide on these directions? As well as considering the local Australian context and its immediate competitors, USQ also examined its future in the broader context of what it observed occurring internationally.

\section{International Influences}

The Internet has already had a major influence on the growth of international education, especially as the cost of access to information communication technologies (ICTs) continues to fall. This decline in costs has also been evident in the telecommunications industry. As Cairncross (1997) predicted, "The death of distance as a determinant of the cost of communications will probably be the single most important economic force shaping society in the first half of the next century” (p. 28).

It is in this context of the rapid increase in institutions offering courses via the Internet and associated user pays for quality service that higher education has become increasingly market driven. The transition from the Industrial to the Information Age has been traced by Dolence and Norris (1995), who argue that to survive organizations need to change from rigid, formula driven entities to organizations that are "fast, fluid, and flexible." Indeed, many universities are struggling to come to terms with the imminent organizational development challenges posed by competition for students through the emergence of the global lifelong learning economy.

The fact that the present traditional approaches based on conventional, classroom-based teaching and learning are not capable of meeting the escalating demand for higher education in the knowledge society has failed to register in the minds of many higher education institution leaders. 
Conventional, classroom-based approaches to higher education are increasingly becoming economically unsustainable. In many areas of the world, we cannot build educational institutions and develop teachers at a fast enough rate to meet the growing demand for all levels of education, including higher education (Bray, 1998). The major challenge confronting university leaders is how to boost academic productivity - how to change the fundamental structure of teaching and learning through the integration of ICTs. There is an immediate need for major investments in ICT and an associated proactive commitment to organizational development and institutional transformation in higher education.

\section{Local Influences}

In recent years, USQ has constantly examined the changing costs of its educational operations, particularly as the breadth of its activities internationally has significantly increased. Given its relatively modest budget and resources, USQ must target its activities carefully to ensure sustainable and quality education provision. Recent information demonstrated that conventional classroom approaches in certain disciplines requiring specialist equipment and facilities were difficult to sustain where class numbers are low (University of Southern Queensland, 2004a). In addition, while revenue from international activities had risen substantially in recent years, the overall costs associated with delivering and supporting teaching in many instances proved quite expensive when traditional models of face-to-face tuition were adopted (University of Southern Queensland, 2004a).

What has this meant for higher education institutions like USQ? Such changes have led to the ascendance of distance education methods through the evolution of all traditional universities into dual mode institutions, offering e-learning courses, and supporting both on-campus and offcampus students through Internet-based delivery systems. USQ's history in distance education enabled it to recognize its potential position to adapt its teaching and learning infrastructure and delivery methods, and to be better placed to become a more important player in a global education environment.

The USQ approach is unashamedly proactive and based on embracing new technologies, fundamentally rethinking and rewiring structure and infrastructure to become a more accessible university in a rapidly emerging e-world. While the USQ approach is clearly a function of the specific institutional characteristics and unique personalities that contribute to the ethos of a particular institution, as a case study it highlights the fact that, to effect the qualitative change necessary to accommodate the online teaching and learning process, it is also necessary to generate qualitatively different organizational infrastructures.

The USQ approach is also strongly based on Taylor's (2001a) fifth generation distance education theory (see also Nunan; Reid, this issue). Although a detailed account of this description is beyond the scope of the present paper, it is fair to say that USQ's distance education operations have progressively evolved through four generations: first, the correspondence model based on print technology; second, the multimedia model based on print, audio, and video technologies; third, the telelearning model, based on applications of telecommunications technologies to provide opportunities for synchronous communication; and fourth, the flexible learning model based on online delivery via the Internet. A fifth generation, derived from the fourth, capitalizes on the database and structured storage and presentation capacity of Web-enabled content and interaction (Taylor, 2001a).

Taylor has worked at USQ for over 25 years and believes that fifth generation distance education has the potential to decrease significantly the costs associated with providing access to 
institutional processes and online tuition. Through the development and implementation of automated courseware production systems, automated pedagogical advice systems, and automated business systems, the fifth generation of distance education has the potential to deliver a quantum leap in economies of scale and associated cost effectiveness. Further, the effective implementation of fifth generation distance education technology is likely to transform not only distance education, but also the experience of on-campus students (Taylor, 2001a). Taylor was able to convince senior management at USQ of the need to change its traditional philosophy and approaches to educational delivery. Consequently, USQ adopted the challenge and used enterprise systems as a key lever in the development of its fifth generation capabilities.

\section{USQ University-wide Enterprise Systems}

The use of university-wide enterprise systems as mechanisms to help attain USQ's specific objectives has been critical to the university's continued financial viability and growth. Specifically, enterprise systems have been pivotal to the concept of an 'e-university,' which offers a range of cooordinated services and access to resources through integrated enterprise systems, and have been fundamental to the university's administrative, teaching and learning, and student support functions. The e-University Project was conceptualized in terms of three fundamental foci: the e-Information repositories; a variety of e-Applications; and the e-Interface respectively. A graphic overview of USQ’s e-University Project is presented in Figure 1.

Figure 1. USQ e-University Project Overview

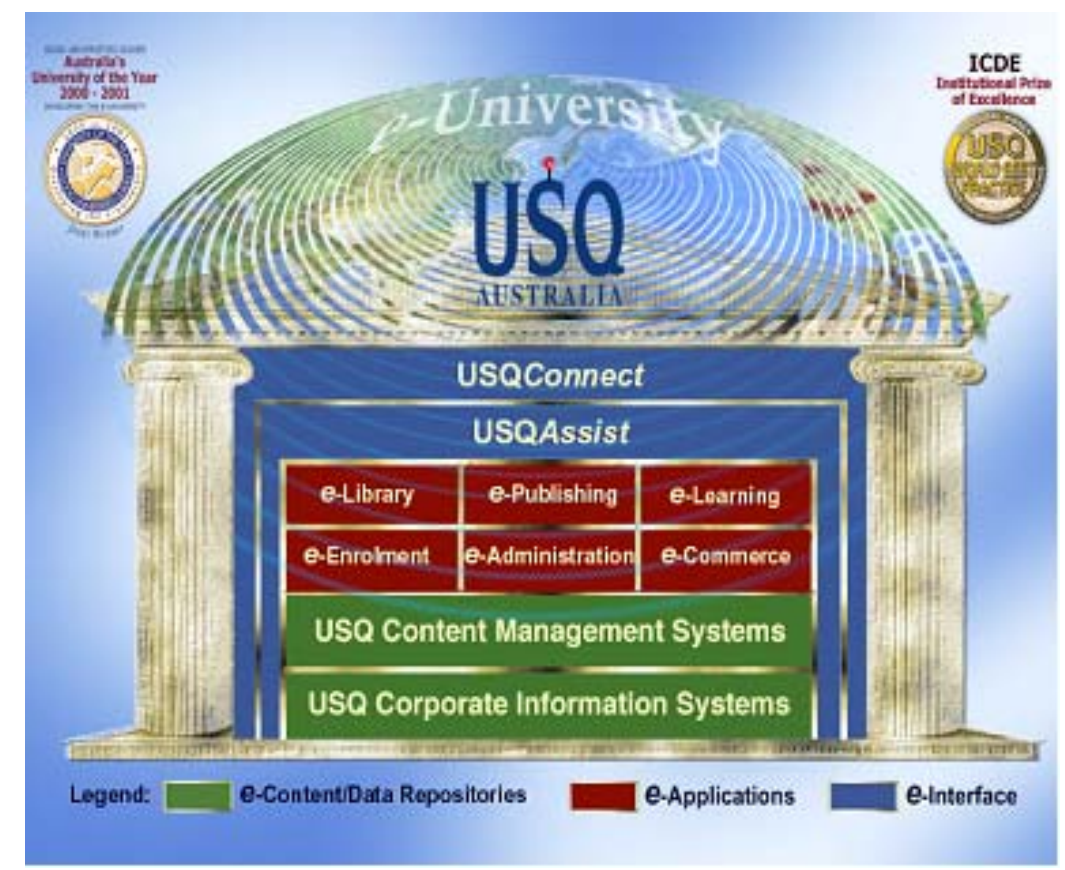

At the base of the 'e-temple' are the USQ corporate information systems which control the university's finance, student administration, and human resource functions. In mid 1999, USQ selected the PeopleSoft enterprise software to replace its existing systems, which required major updating both in scale and in functionality. The implementation of the PeopleSoft software modules (finance, student administration, and human resources) was completed early in 2002. Figure 2 shows the interface developed to access USQ's PeopleSoft Student Administration system. 
Figure 2. USQAdmin Interface

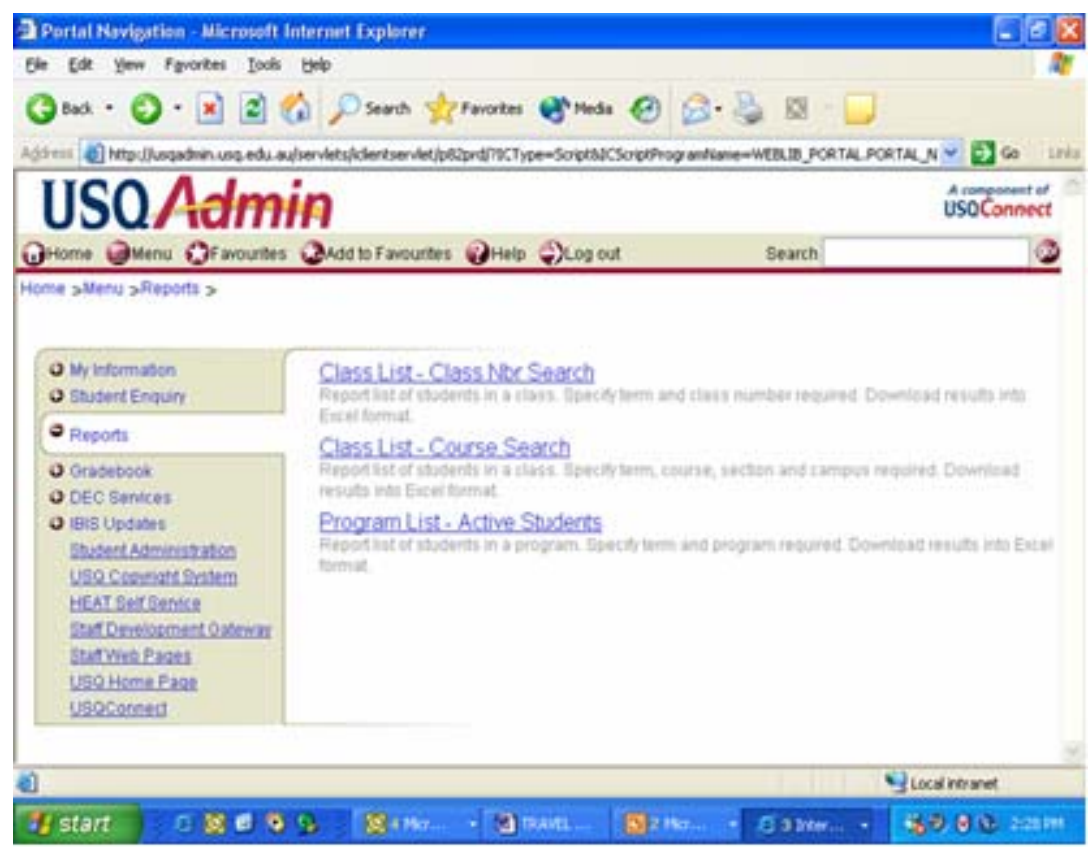

The continuing relationship with PeopleSoft will ultimately lead in 2005 to the implementation of PeopleSoft Version 8.0, which is fully Web-enabled and therefore consistent with USQ's strategic commitment to the e-University Project. Prior to the implementation of PeopleSoft 8.0, the existing integrated applications will provide an essential source of e-information in conjunction with the e-content management system at the heart of the Generic Online Offline Delivery (GOOD) Project, an application developed locally at USQ. Figure 3 demonstrates the basic functionality of the GOOD System.

Figure 3. GOOD System Functionality

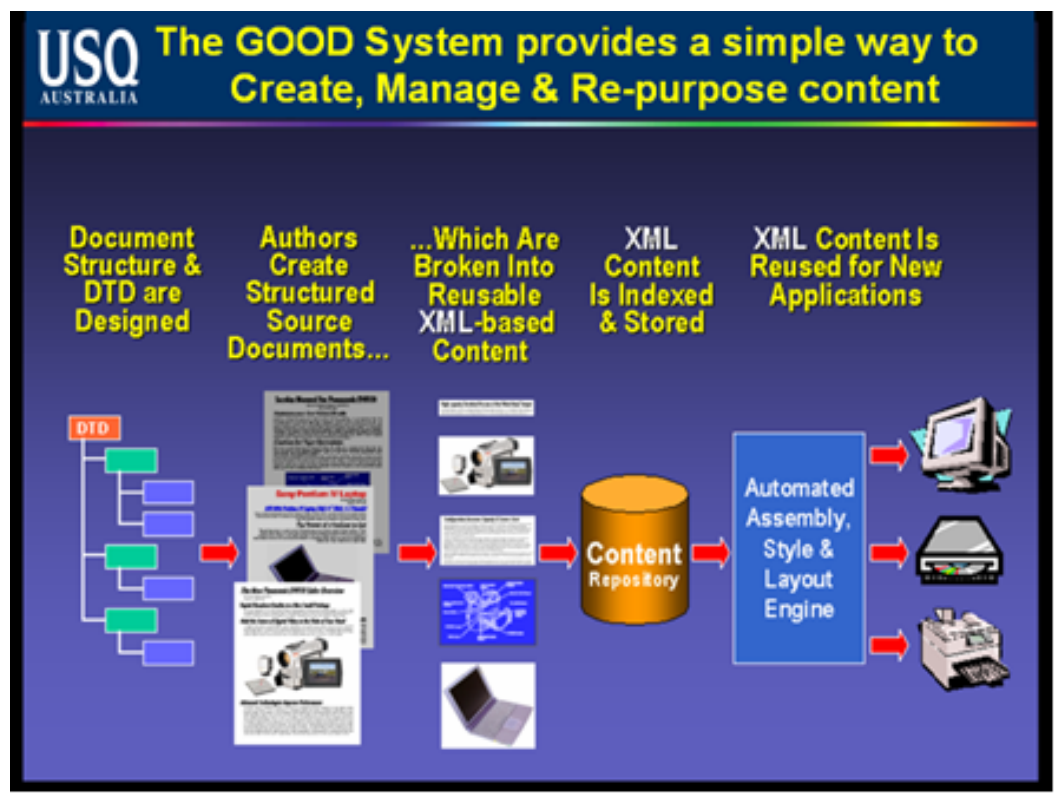


In essence, the e-content management system incorporated in the GOOD Project enables crossmedia publishing from a single document source. This means that USQ is able to make courseware available to students in a variety of delivery modes (print, online, CD, DVD, etc.) from a single document source. At the core of the GOOD cross-media production system is a content management system, which provides an integrated document management, workflow, and a content editing environment. Further, the cross-media publishing process has been automated through the use of standard markup languages. The GOOD project is gradually enabling USQ to replace its resource intensive proprietary production system for courseware with a single document source system based on the XML (Extensible Markup Language) standard. XML-tagged courseware documents are structured within consistent, comprehensive parameters, with the substantive content and structure able to be treated discretely from layout and presentation. The document layout is generated by applying XSL (Extensible Stylesheet Language) to the XML-tagged content. While initially focusing on the cross-media production of courseware and the university handbook, in time the GOOD system is being progressively rolled out to other areas across the university, including the cross-media publication of course information, admissions and enrollment documentation, and the like. Figure 4 shows the course materials production process using the GOOD System.

Figure 4. GOOD System Course Materials Production Process

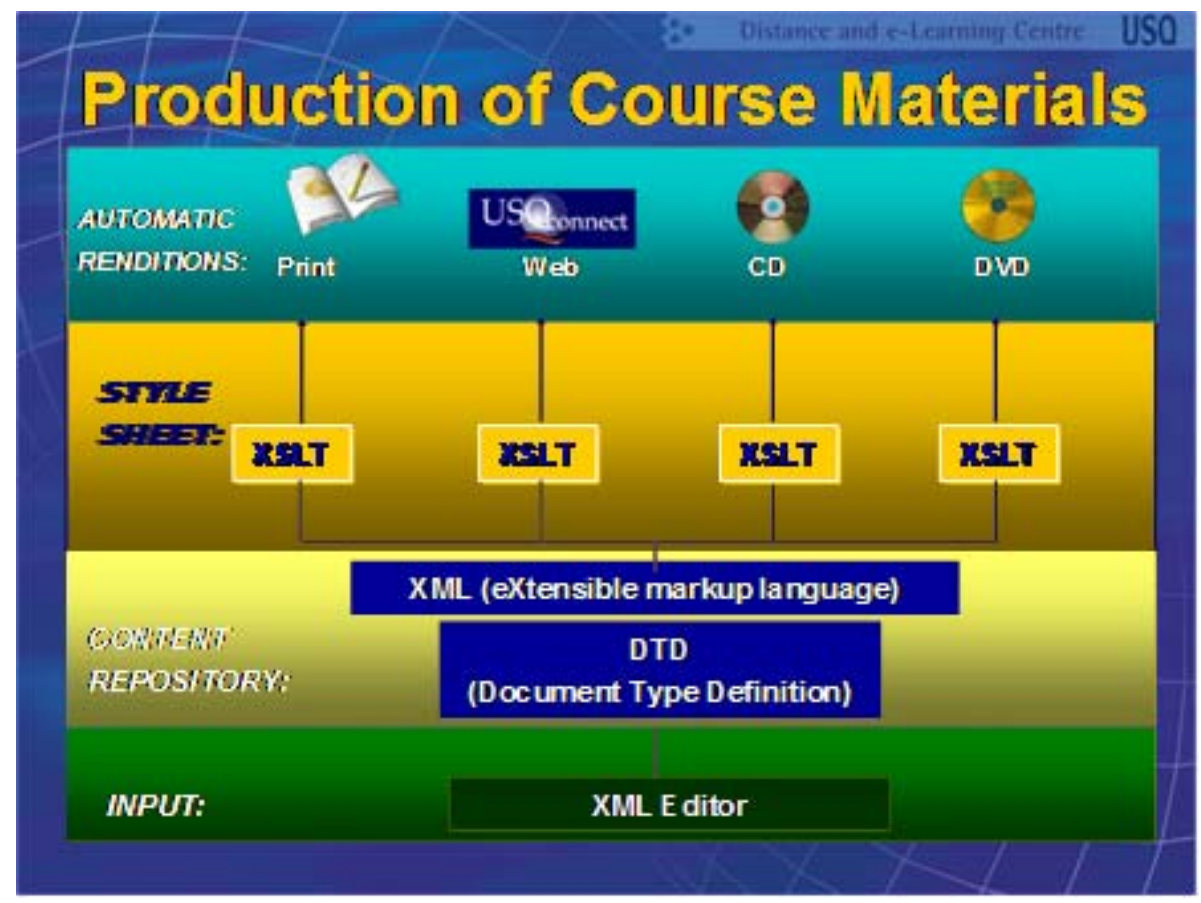

While the GOOD system provides a critical foundation for the efficient development and delivery of courseware, it also provides an integral 'engine' for the provision of a range of e-applications, including e-Enrolment, e-Administration, e-Commerce, e-Publishing, and not least e-Learning. This is supplemented by a Web content management system which maintains the corporate level information contained on the USQ website (see Figure 5 below), ensuring that all information pertaining to critical areas of university business remains up-to-date and accurate at all times, no matter what entry point or method of navigation is used to locate that information. 
Figure 5. USQ Website Interface

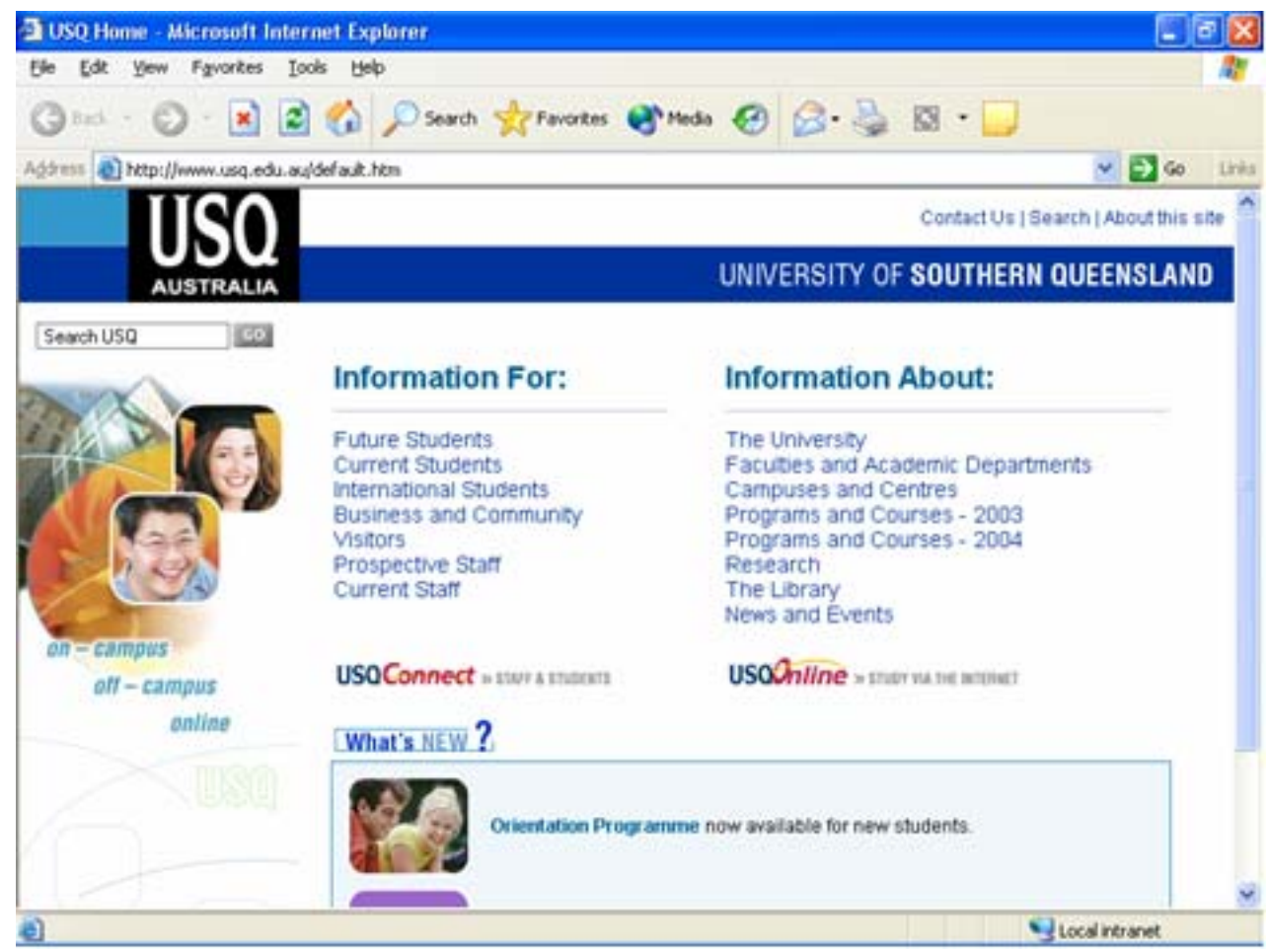

Course materials are delivered to USQ students in a variety of ways, depending on the mode selected, location of students, or contractual arrangements with selected USQ partners. There is now an expectation that all students will have the use of a minimum standard of hardware, communications software, and Internet access to undertake their studies. Some specific programs and courses have particular computing requirements above these general minimum requirements. With the use of learning managements systems such as Blackboard and more recently WebCT Vista (see also Cummings, Phillips, Tilbrook, and Lowe; McConachie, Danaher, Luck, and Jones, this issue), all USQ courses, regardless of delivery mode, have the option of providing both essential and/ or supplementary study materials, as well as the use of communication tools such as asynchronous discussion forums and virtual chat sessions as part of course delivery. This in turn has spawned the development of new 'hybrid' forms of delivery, where the elements of the study package are provided to all students and a range of different learning activities are facilitated in various modes, including online and face-to-face where appropriate. This has resulted in the emergence of new and innovative pedagogies across several disciplines and a significant change to teaching styles and classroom organization. Figure 6 below shows the types of activities which support the resource-based learning models being developed at USQ. Figure 7 shows the WebCT Vista learning management system interface being used by USQ. 
Figure 6. Hybrid Delivery Options

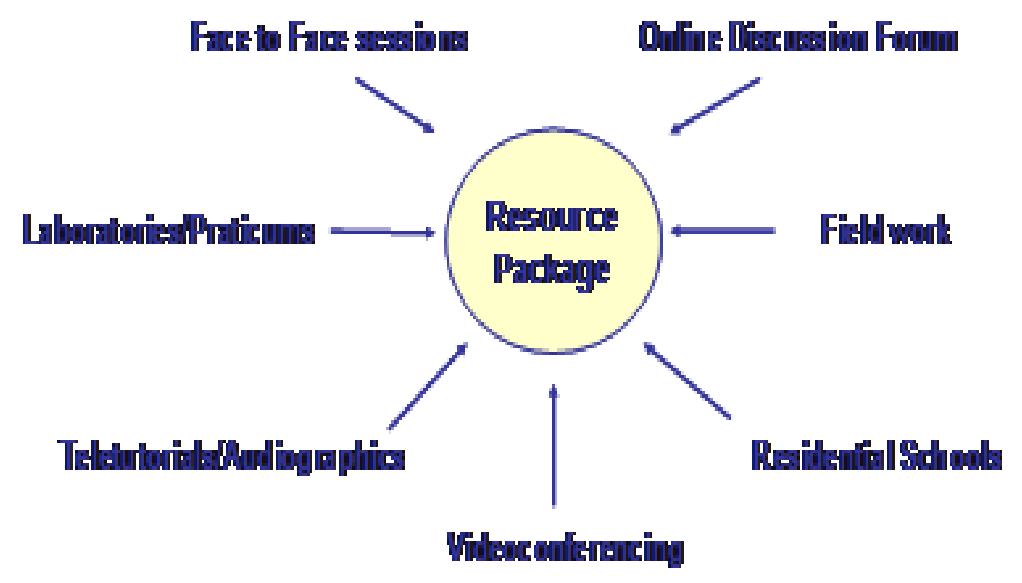

Figure 7. USQStudyDesk Interface

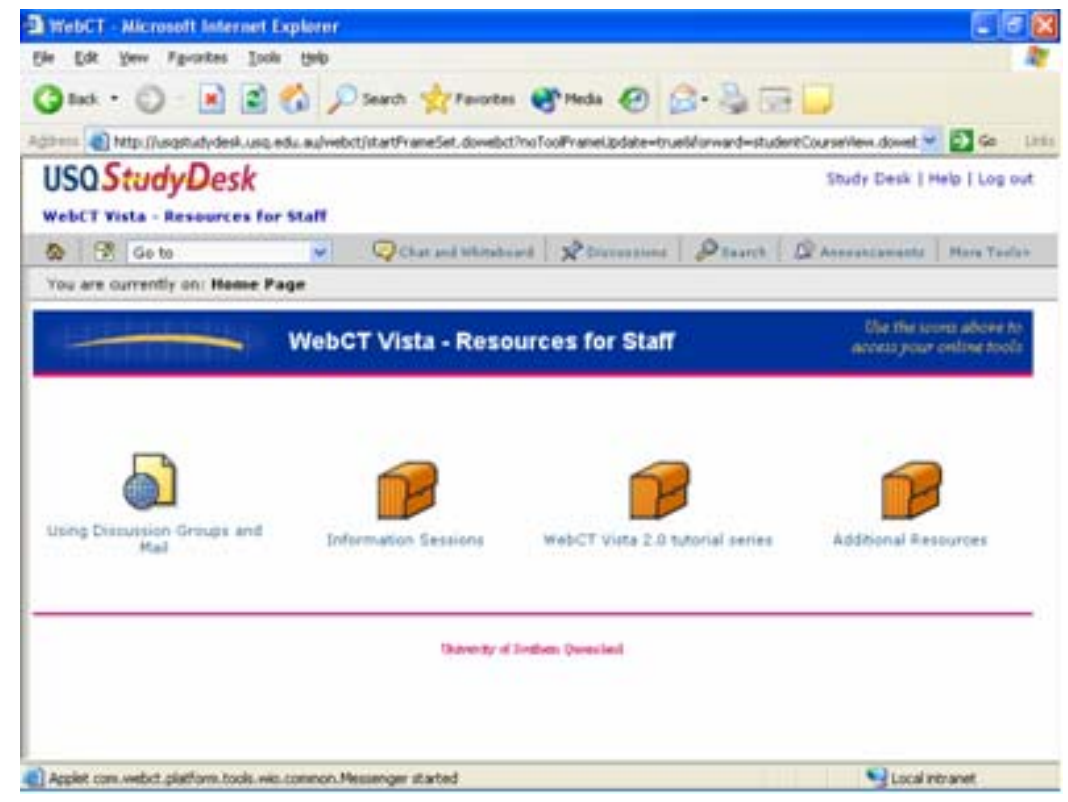

While the use of these enterprise systems at USQ has contributed significantly to the development of new pedagogies, it is in the area of student support that they have made perhaps the most significant difference. The USQ approach to learner relationship management has incorporated technologies to automate certain aspects of interaction with students, ultimately improving cost effectiveness, reducing both response times and costs to students and potentially increasing access to higher education on a global scale.

The USQAssist initiative deploys tracking and automation tools to manage the interaction between the university and both its existing and its prospective students. As USQ already has a need to provide global learning services to students enrolled in more than 100 countries, the university has to face the challenge of being responsive to client needs 24 hours per day, 7 days per week. The most efficient, cost effective way to manage the 24/ 7 challenge is to deploy 
effective automation tools, as opposed to running three shift student service desks or employing online tutors in different continents (although USQ already does the latter). The aim of such a system is to provide effective and efficient service to existing and prospective students at minimal variable cost.

When the project was initiated in late 1999, there were 13 toll free telephone numbers and numerous help desk facilities offered by various sections of the university. Each of these services provided a valuable service and collected some useful information, but there was no systematic recording and processing of enquiries that would enable USQ to be more responsive to satisfying student needs. The deployment of e-Customer Relationship Management (e-CRM) software will ultimately enable the use of a single toll free number integrated with an email-based enquiry tracking system that will exploit the fundamental strengths of the Internet in enhancing communication and managing information. Using structured, intelligent databases, the knowledge generated by solving student problems/ enquiries is being progressively stored and made available so, wherever possible, students with equivalent or similar problems can have their enquiries dealt with immediately through the self-help, automated response capacity of the USQAssist system, thereby facilitating effective first point of contact resolution (Taylor, 2001a) (see Figure 8).

Figure 8. Schematic Representation of USQAssist

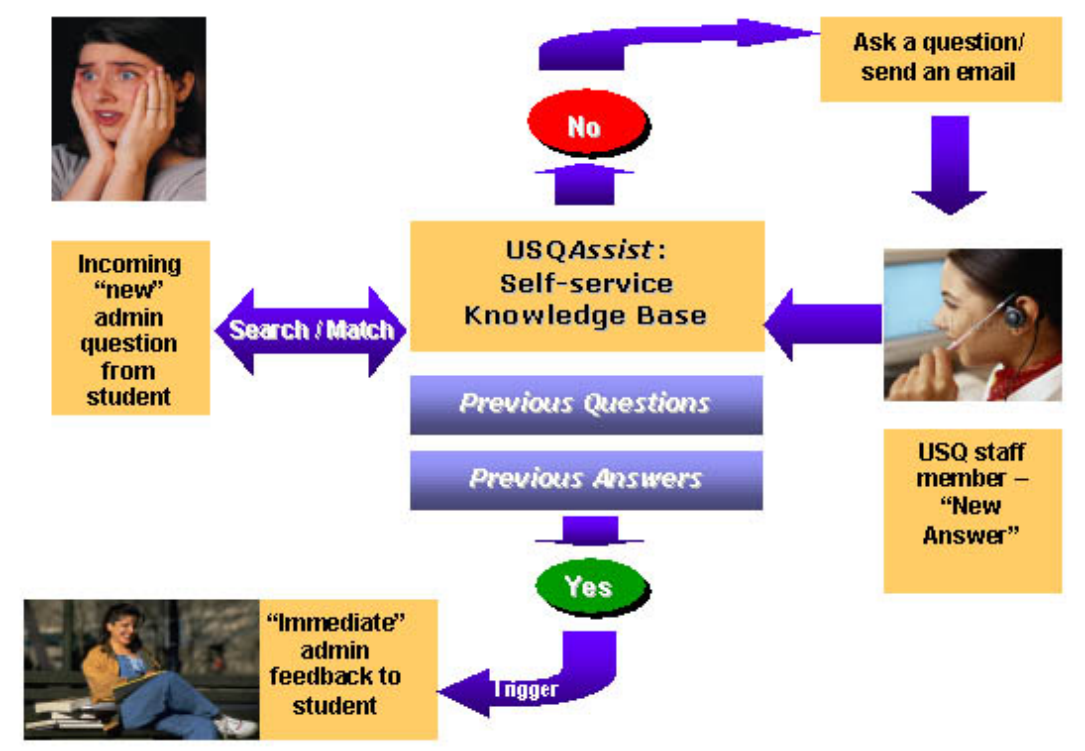

As the dynamic knowledge databases become more comprehensive, enabling personalized, immediate responsiveness to an increasing number of student queries, the institutional variable costs for the provision of effective student support further reduces. The judicious use of such technology not only improves the responsiveness of the institution, but also frees up student support personnel to provide personal assistance via email dialogue or telephone as necessary. Further, every interaction is tracked from initiation to resolution, including flexible routing of enquiries based on explicit rules-based escalation protocols to ensure timely and successful responsiveness, and subsequent statistical reporting of system performance. Tracking interactions with prospective students enables the collation of the effectiveness of institutional marketing strategies, an increasingly important strategic issue for universities in the emerging global learning economy, which demands a highly effective public e-Interface with the university (Taylor, 2001b) (see Figure 9). 
Figure 9. USQ Assist Interface

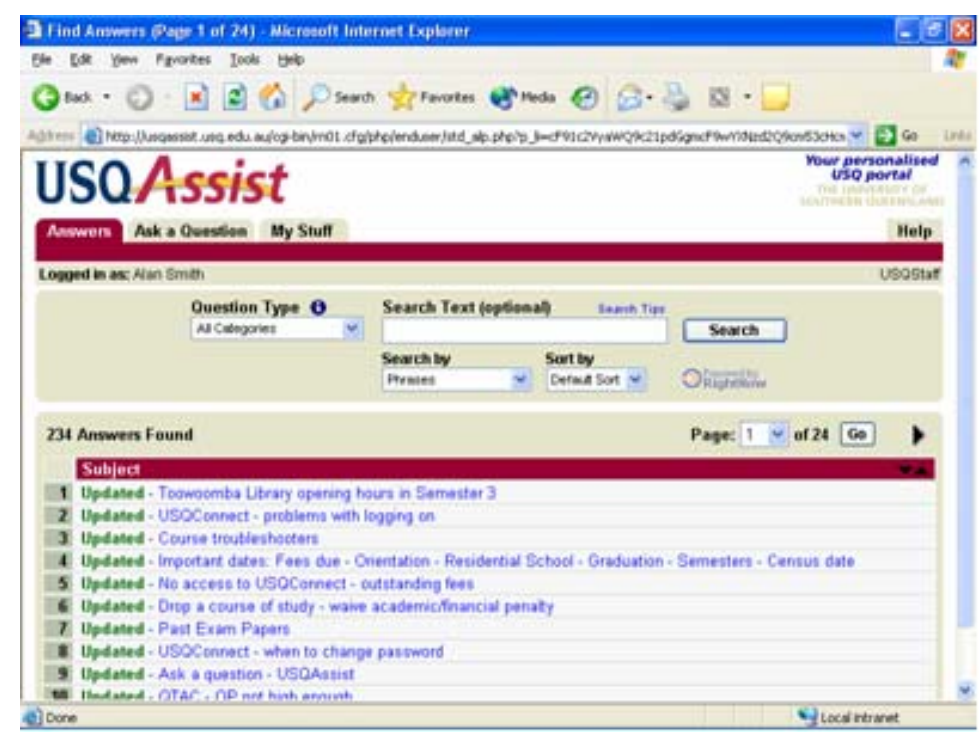

An additional learner relationship management feature of the USQ e-University Project is the development of a customizable e-Interface, a campus portal through which students, staff, and other stakeholders can engage with the university in a highly interactive and compelling manner. To be successful in the emerging global lifelong learning market, a university needs to create a campus portal that will achieve a degree of interactivity, user friendliness, and personalization that does not exist in the vast majority of higher education campus websites at present. The USQ e-Interface has developed through the application of a Web services approach, the implementation of which has entailed the creation of a new Internet Systems Design, Development, and Integration Team. The e-interface allows all students and staff appropriate levels of access to the full range of USQ enterprise systems and their associated services and benefits (see Figure 10 on the next page).

Figure 10. USQConnect Interface

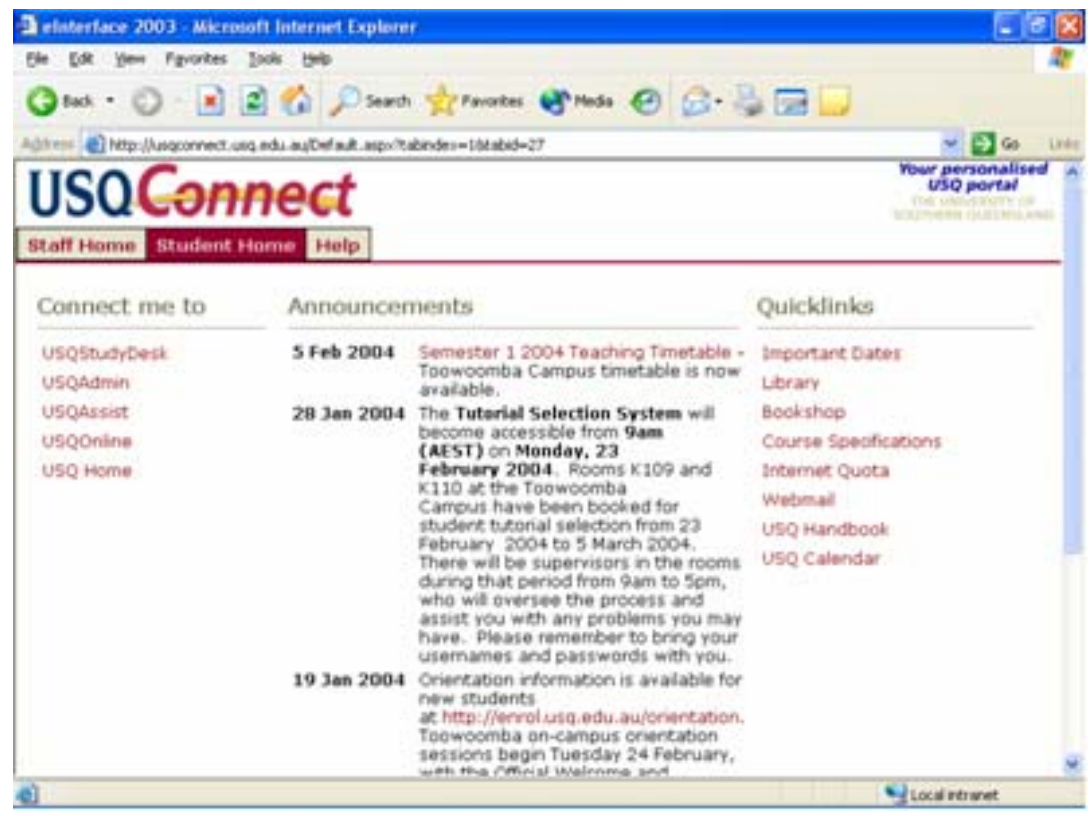


Learner relationship management is further supported by the implementation of USQ's wireless networking initiative. This part of the plan emerged from concerns expressed by on-campus students that they were becoming increasingly disadvantaged by a lack of sufficient access to online resources and services, since the campus-based computing laboratories were devoted primarily to the teaching of specialized software applications, often requiring access to 'high powered' hardware and software. USQ is now in the second phase of the project, with funding allocated to enable the installation of wireless hubs to ensure access to the Internet from about 90 percent of on-campus locations.

The implementation of USQ's wireless networking initiative and the use of integrated enterprise systems have raised important questions about the security of local networks and their susceptibility to attack from hackers and other unwanted intruders. An increasing number of resources has been necessarily devoted to analyzing the vulnerability of USQ IT systems to unauthorized entry from others, ensuring that appropriate backup systems are in place, and working toward single sign on access.

While the use of technology has been important in USQ's development of the e-University Project, the use of horizontal functional teams in a number of these development projects has proven critical to delivering the level of integration and to successful implementation (Gratton, 2000; Ostroff, 1999). Almost all the different aspects of the e-University Project have involved key players from the Distance and e-Learning Centre, Information Technology Services, the Library, and Faculties, together with other stakeholders from areas such as Student Administration, the International Office, Student Support Services and Financial Services. Whether as part of specific e-University project teams or through committees such as the Information Infrastructure and Services Committee, the active participation of a range of individuals and groups with either technical or operational expertise has been essential to the design and development of these new systems and to the relatively smooth implementation of new processes and procedures to key areas of university operations.

Much of this has been assisted by the clear communication from senior management of the need to maximize the functionality of all enterprise systems and to ensure that no single entity in the university makes an individual decision about technology or systems which in any way undermines the strategic directions outlined earlier in this paper. The size of the university, its financial procedures, and its current organizational structures certainly assist in this regard, but it still requires vigilance and regular monitoring by senior management and strategic committees to ensure that appropriate purchases and implementations of technologies takes place.

USQ has derived considerable benefits from its use of enterprise systems. The latest activitybased costing reports show increased student numbers without the 'normal' corresponding increases in student support staff. Importantly, student satisfaction with the quality of university services and systems remains high. Response times are constantly improving and both staff and students are utilizing the additional features and convenience provided by the integrated systems approach. Savings on additional staffing enable more resources to be directed to improvements in infrastructure and the development of new technical solutions/ enhancements to the e-University interface (University of Southern Queensland, 2004a).

\section{Conclusion}

In many universities, the development of Web-based initiatives and the use of enterprise systems are not systematic, but rather are more often the result of acts of innovation initiated by risktaking individual academics or of decisions made by individual faculties or service divisions. By 
contrast, the implementation of the e-University Project at USQ is strategically planned, systematically integrated, and institutionally comprehensive. This organizational culture has evolved over many years, and is essentially a reflection of one of USQ's guiding objectives: “To be a leader in flexible learning and the use of information and communication technologies in the tertiary education sector.”

The USQ case study also demonstrates that technology alone is not sufficient to engender much needed organizational development. If the power of the increasing array of new technologies is to be exploited in higher education, an appropriate organizational development strategy needs to be devised and implemented to bring about necessary institutional reconstruction.

USQ's use of enterprise systems to develop its fifth generation model of distance education (Taylor, 2001a) has enabled it to provide students with a valuable, personalized pedagogical experience at noticeably lower cost than traditional approaches to distance education and conventional face-to-face education. Fifth generation distance education not only has been less expensive, but also provides students with better quality tuition and more effective pedagogical and administrative support services than many other traditional universities.

USQ will continue with this approach and progressively upgrade and replace enterprise systems as licence and maintenance agreements come up for renewal. The objective will be not to be totally dependent on any single vendor, but to be able to select new applications and technologies as they are developed and to integrate them into the university's overall infrastructure and processes. The continuing development of open source technologies will be watched with considerable interest by many, in the belief that they may provide additional alternatives to the current proprietary enterprise systems.

\section{Postscript}

The quality and standing of USQ's teaching and learning activities have been widely recognized both nationally and internationally. In 1999, the Executive Committee of the International Council for Open and Distance Learning awarded USQ the Inaugural Institutional Prize of Excellence for a dual mode institution in recognition of both the university's significant contribution to providing education at a distance to the world and its leadership and innovation in the field of distance learning (see also Reid, this issue).

In August 2000, USQ was joint Winner of the Good Universities Guides 'University of the Year' for 2000-2001. The Award recognized USQ's leadership in developing the 'e-university' where students learn and are supported through the innovative and strategic use of educational Webbased technologies that encourage e-world expertise. The university has also won a Commonwealth of Learning Award of Excellence for Institutional Achievement at the third PanCommonwealth Forum on Open Learning held in Dunedin, New Zealand, in July 2004 specifically for its provision of flexible learning opportunities for people with diverse social and cultural backgrounds.

\section{References}

Bray, M. (1998). Financing Education in Developing Asia: Issues, trends and policy implications. Manila, Philippines: Asian Development Bank.

Cairncross, F. (1997). The death of distance. In O. Morton (Ed.) Exploiting the Information Age. London: Profile Books. 
Dolence, M. G., and Norris, D. M. (1995). Transforming Higher Education: A vision for learning in the 21st century. Ann Arbor, MI.: Society for College and University Planning.

Gratton, L. (2000). Living Strategy: Putting people at the heart of corporate purpose. London: Prentice-Hall.

Ostroff, F. (1999). The Horizontal Organization. New York: Oxford University Press.

Taylor, J. C. (2003). USQOnline, Australia. In S. D’Antoni (Ed.) The Virtual University: Models and messages. Lessons from case studies. Paris: Institute for Education Planning, UN Educational, Scientific and Cultural Organisation.

Taylor, J. C. (2001a). 5th Generation Distance Education (Higher education series, Report no. 40). Canberra, ACT: Higher Education Division, Department of Education, Training, and Youth Affairs.

Taylor, J. C. (2001b). The Future of Learning - Learning From the Future: Shaping the transition. Open Praxis, 2, 20 - 24.

University of Southern Queensland. (2004a). USQ activity based costing report 2004 (Internal working paper). Toowoomba, QLD.: Author.

University of Southern Queensland. (2004b). USQ directions 2004 (Internal working paper). Toowoomba, QLD.: Author.

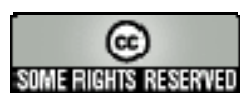

